\title{
Som não é uma coisa em si, e sim o transporte de coisas que
}

vazam

\author{
Rodolfo Caesar \\ Universidade Federal do Rio de Janeiro \\ rodolfo.caesar@gmail.com
}

Resumo: Crítica à noção de "som", tal qual, vernaculamente - mas sobretudo entre artistas e músicos do mundo ocidental - a construímos e entendemos. A experiência de escuta tem sido construída de maneira a quase podermos ver os "sons", como se fossem objetos (nem sempre identificados) voando no espaço. Esse texto apresenta uma tentativa para devolver um pouco da integridade dessa experiência.

Palavras-chave: Objeto Sonoro. Sonoridade. Sentidos. Psicologia do Espaço.

\section{Sound Isn't a Thing in Itself, but a Carrier for Leaking Things}

Abstract: The listening experience has been studied and described in ways that it is almost as if one could "see" sounds as objects flying in a space - most of them fortunately unidentified. I will juxtapose a few propositions which, for some years, I have been dealing with and writing about, trying to sum these articles" intentions in one and the same: to prevent us against the faith on the neutrality and the universality of cultural constructed perceptions, and to recover a more wholesome mode of listening - if not in the general day-to-day life, at least in the artistic field.

Keywords: Sound Object. Sonority. Senses. Psychology of space.

“...Nunca fui tão tocado, quase movido, como à vista da urze, no outro dia, quando encontrei esses três ramos em sua querida

carta. Desde então não saem do meu Livro de Imagens, penetrando-o com seu odor sério e forte, que nada mais é do que a

fragrância da terra no outono. Quão gloriosa, essa fragrância.

Nenhures, me parece, a terra se deixa toda cheirar em uma inalada, a terra madura; em um odor que em nada é menor que o do mar, amargo aonde beira o sabor; e mais que doce, quando se sente perto de tocar os primeiros sons. Contendo profundidade em

si, escuridão, algo quase grave, e ainda: vento, alcatrão e terebintina, e chá do Ceilão. Sério e baixo como o cheiro do monge mendicante, mas também terrestre e resinoso como o precioso incenso". (RILKE) $)^{1}$

\footnotetext{
${ }^{1}$ Tradução do autor, do original: "Never have I been so touched and almost moved by the sight of heather as the other day, when I found these three branches in your dear letter. ... But how glorious it is, this fragrance. At no other time, it seems to me, does the earth let itself be inhaled in one smell, the ripe earth; in a smell that is in no way inferior to the smell of the sea, bitter where it borders on taste, and more than honeysweet where you feel it is close to touching the first sounds. Containing depth within itself, darkness, something of the grave almost, and yet again wind; tar and turpentine and Ceylon tea. Serious and lowly like the smell of a begging monk and yet again hearty and resinous like precious incense" (RILKE; AGEE, s. d.).
} 
Sons

Este texto se endereça a setores das artes, incluindo a música, que tratam, discutem, manipulam ou se apropriam do chamado "som". Entendo, este, como resultado de uma construção de nossa cultura ocidental, atualmente celebrado por artistas e músicos contemporâneos. A ação de escuta tem sido estudada e descrita, algumas vezes, como se pudéssemos "ver" seus produtos - os sons - como objetos voadores no espaço. Neste artigo eu gostaria de retomar alguns tópicos com os quais tenho lidado desde que me iniciei na música eletroacústica e na Sonologia. Creio que, mostrando como, no século XX e XXI, se deu a conformação desse ser, poderei contribuir para que não se acredite mais na escuta de sons como sendo uma percepção neutra e universal. Com isto, talvez consiga recuperar uma percepção mais integrada.

Desde os tempos de Heráclito, acreditou-se que não há uma percepção (e compreensão) integral do que seja o mundo. Somos, quando muito, capazes de conceber, e ocasionalmente compartilhar, algumas partes e fatias, alguns ângulos e momentos, raramente os mesmos, sempre partes de um todo. Nossas cenas artísticas e culturais ocidentais costuma haver uma confusão entre a parte e o todo, especificamente quando lidamos e discorremos sobre a escuta. A despeito de conquistas de musicologias pósmodernas (MCCLARY, 1991; SUBOTNICK, 1995; DELL'ANTONIO, 2004), nossa escuta parece ter estacionado numa atitude em que se toma a parte pelo todo. Esses estudos expuseram com diferentes graus de objetividade as motivações sócio-políticas que construíram a escuta moderna. Longe de rejeitá-los, este texto tende mais para o enfoque de uma Sonologia, uma pesquisa sobre a escuta em um plano "meramente perceptual”, porventura para provar que tal plano tampouco existe.

Experiências de percepção sonora, nas artes, são, ainda hoje, apressadamente classificadas conforme tipos, sensações e formas, sendo, assim, apenas estruturais e parcialmente vividas. Discorrer sobre a escuta é mais complicado, como pretendo demonstrar. No entanto, mais difícil ainda é falar dos outros sentidos, aos quais a cultura ocidental reservou menor quantidade de literatura, como o olfato, o tato e o paladar (daí ser possível pensar que exatamente por esse motivo eles tenham eventualmente algum "mistério" a nos revelar...). 
A tarefa de descrevê-los e classificá-los se tornaria infinitamente mais complexa se conseguíssemos romper com a concepção delimitadora que os divide abruptamente. A clássica divisão em número de cinco ainda é aceita em quase todas as esferas do conhecimento ocidental. Por conta dela, confundimos as percepções com os lugares do corpo em que elas se concentram com maior intensidade. Quanto ao conhecimento da escuta isolada, este não pode levar em conta toda a complexidade envolvida no ato de escutar, ignorando o quanto ele, e cada um dos demais sentidos, pode ser interpenetrado e dependente dos outros.

Não é difícil admitir que, quando funcionando em modo default (DENNETT, 1991; ALBAHARI, 2006; POLLAN, 2013), a mente atua por separações. Para que o nosso raciocínio lógico processe, precisamos distinguir, nas coisas, um todo de suas partes constituintes. Sendo assim, presume-se que o mesmo procedimento separador regule os objetos de nossos sentidos, isolando-os conforme se detecte pelo menos uma parte que nos seja familiar. Quando vemos partes de alguma coisa e as tomamos pela integridade da própria, isso pode levar a enganos. A despeito de não duvidarmos mais da sinestesia e da transmodalidade (MERLEAU-PONTY, 1945) ou, como prefere Michel Chion, a transsensorialidade (CHION, 1998), há uma tendência em discorrer sobre a escuta como se fosse autônoma. Simplificamos, reduzindo nossas experiências. Por meio do isolamento individualizado dos sentidos, tendemos a acreditar mais naquilo que podemos objetificar, aceitando, por credulidade nessa tomada parcial, a experiência deles pela do todo.

Um poeta como Rilke celebra o indissolúvel, conforme a epígrafe. Mas o objetivo desse ensaio não é reacender o interesse pelo simbolismo, e sim convidar à reflexão sobre a escuta, seja ela orientada a sons, a músicas ou a ruídos, mostrando como é difícil classificar o que se escuta, e como o método mais usado para isso - se insistirmos na redução - é passível de erro.

Antes, porém, de aprofundar o tema, preciso enfatizar que esse artigo não tem a intenção de alavancar a noção de que somente experiências "totais" deveriam ser o propósito das artes. Em seu tempo, Wagner já o dizia. Falta, aqui, um pendor para pontificar sobre o que se deve ou não fazer. E a noção de totalidade sempre assusta. $\mathrm{O}$ que motiva essa escrita é entrelaçar comentários que nos façam lembrar de como algumas das artes, inclusive no segmento chamado Música Contemporânea, lidam com um 
limitado aspecto, retirado de dentro do vasto universo sonoro. Na minha opinião, esse recorte se deve a interferências implicadas na maneabilidade tecnológica e no poder de controle de quem manuseia. Quando abandonamos as certezas indispensáveis para a manipulação dos "sons", esses "objetos sonoros", chegamos mais perto da capilaridade das parcialidades, das incertezas, da fugacidade dos momentos, e aí recuperamos um sopro heracliteano, enriquecedor da escuta.

\section{Som}

Diversos dicionários de variadas línguas concordam que a palavra "som" significa algo como "vibrações que viajam através do ar ou outro meio, que podem ser escutadas quando alcançam o ouvido de uma pessoa ou animal". ${ }^{2}$ Em estilo mais cartesiano, outra edição afirma o som é uma "energia mecânica radiante transmitida por ondas de pressão longitudinal num meio material (como o ar). Sendo esta a causa objetiva da escuta". ${ }^{3} \mathrm{Um}$ curto estudo terminológico confirma que o som é entendido de variados modos, tendo passado por diversas transformações ao longo do tempo, e conformando-se a idiossincrasias locais, não apenas acadêmicas, mas também vernaculares. De um cômputo geral entre as diferentes versões, emerge uma noção que quase fala dos sons como se fossem corpos voadores correndo pelo ar. Submetido a um longo processo de objetificação, essa "coisa" perde no caminho alguns de seus mistérios. Na acepção corrente, esse som implica numa incapacidade de aceitação ou uma recusa da integridade da experiência, daí meu desejo de lançar alguns tópicos de discussão, sempre evitando a ambição de escrever uma história completa da escuta.

Certamente a construção desse "som" recebeu um grande impulso após o surgimento das tecnologias fonográficas, gramofônicas e de rádio e sua proliferação no ambiente doméstico (IAZZETTA, 2009). Ao longo dos séculos, construímos um som particular e incompleto, em cuja materialidade hoje se operam manipulações artísticas e controle espacial, seja na horizontal, na longitudinal e/ou na vertical em concertos eletroacústicos - ou super amplificados por $x$ decibéis nas artes que dependem de volume.

\footnotetext{
2 "Vibrations that travel through the air or another medium and can be heard when they reach a person's or animal's ear". https://en.oxforddictionaries.com/definition/sound.

3 "Mechanical radiant energy that is transmitted by longitudinal pressure waves in a material medium (such as air) and is the objective cause of hearing". https://www.merriam-webster.com/dictionary/sound.
} 
Uma noção de que o som é uma coisa se desenvolve em associação com a disseminação dessas tecnologias no domínio da música, juntamente com as artes sonoras, visuais, de vídeo e cinematográficas e suas ferramentas técnicas. Essa cultura sonora segue em paralelo a uma linha análoga à daquele processo mais antigo de "fatiar" a percepção, ou seja, isolar cada um dos sentidos em seu cercado fechado. Asim se operou a segregação da visualidade, que tem sido central na cultura ocidental desde o seu início. Aproximando-me do lema da conferência (I/O) ${ }^{4}$, tentarei mesclar dois polos teóricos do som, o "interno" e o "externo" - na minha opinião, inseparáveis, apontando como as tecnologias da cultura ocidental participaram de sua construção. É necessário examinar esse "som em si", ou "som", o "objeto sonoro" no contexto artístico, para entendê-lo como consequência de um processo complexo, e não como um fenômeno natural, como tem sido o caso.

\section{Sensações mistas}

Todos sabemos muito sobre conexões perceptivas como a sinestesia - já comentada por muitos autores - e suas percepções mistas complementares, como a trans-sensorialité de Michel Chion, devolvendo a transmodalidade de Merleau-Ponty. Ritmo, por exemplo: a qual sentido pertence?

Mas há mais complexidade a ser observada em nossos sentidos, iniciada com a anexação de uma nova paleta ao grupo clássico de cinco. Há um aumento importante, e talvez mais por vir: propriocepção, equilíbrio, dor, estimulação sexual, etc. todos hoje em dia considerados sentidos no mesmo grau que os cinco aristotélicos.

Além dos escritos de Rilke, pesquisando na internet descobre-se que no domínio das neurociências existem pesquisas (ZHOU et al., 2010; MAIER et al., 2015; WALLACE, 2015) levando à ideia de que a percepção se constitui de um único sentido, funcionando de acordo com as interconexões de dois ou mais aparelhos perceptuais (olhos, ouvidos, etc.). O neurocientista Donald Katz escreveu sobre a interdependência entre olfato e paladar, concluindo se afetam mutuamente. Isso não é novidade para a maioria dos conhecedores de vinhos, assim como para os perfumistas (ROUDNITSKA,

\footnotetext{
${ }^{4}$ Originalmente, esse artigo foi apresentado em sessão de Comunicações no evento SONOLOGIA: International Conference on Sound Studies I/O, em 2019, organizado pelo NuSom - Centro de Pesquisas em Sonologia, da ECA/USP.
} 
1977). A percepção transmodal de Merleau-Ponty e a trans-sensorialité de Michel Chion não estão em desacordo. Fiquei visualmente convencido ao prestar atenção ao "sorriso" desse animal na foto, e, mais tarde, novamente ajudado pela internet, aprendi sobre a atitude de atenção perceptiva chamada, em alemão, flehmen. Este felino está "flehmen": misturando dois de seus sentidos, o olfato e o paladar, para mútuo reforço.

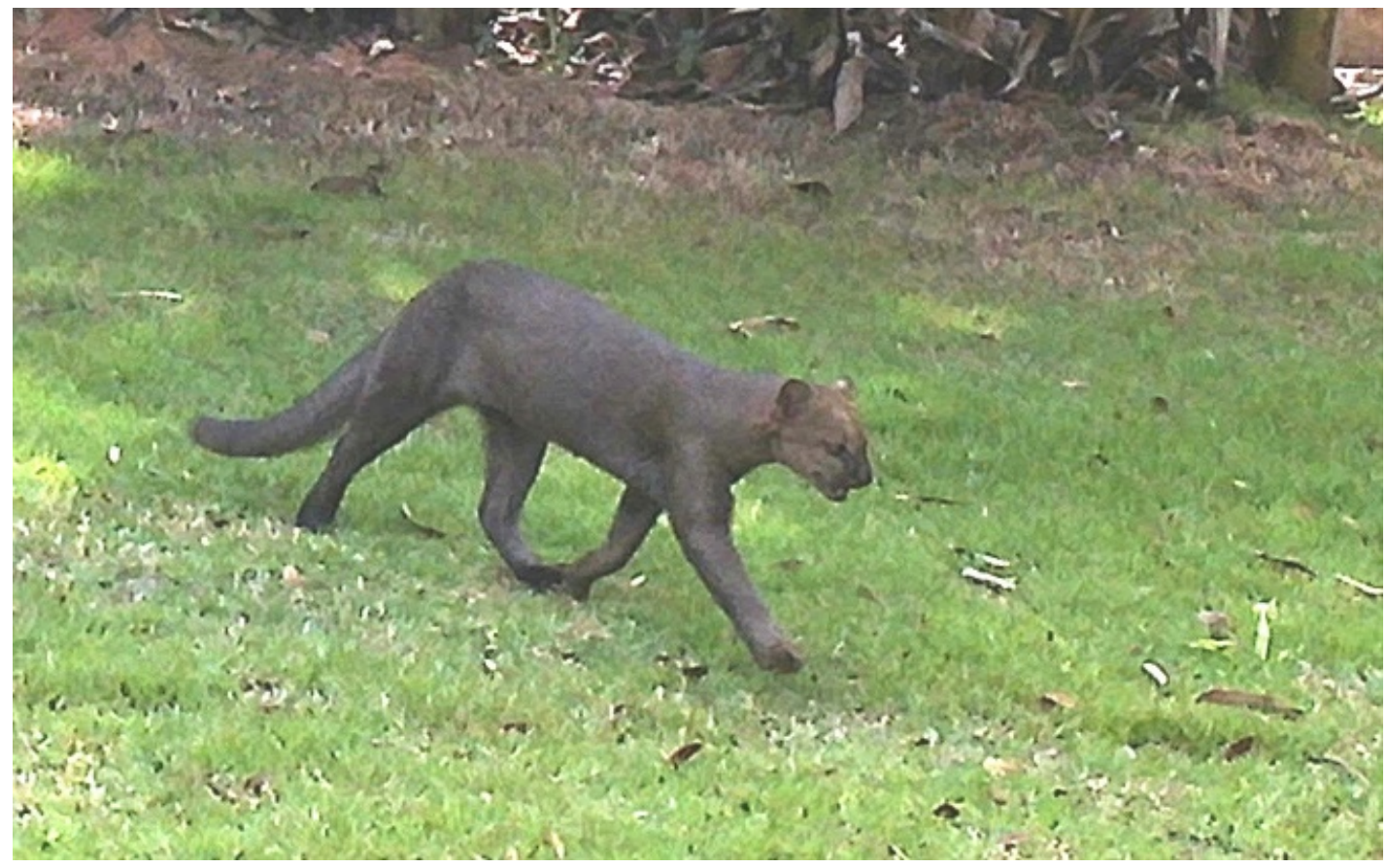

Fonte: "autorretrato" obtido por sensor de presença, acervo do autor.

A interpenetração, ou a colaboração entre sentidos, corrobora um ensaio no qual reconheço os limites de fusão entre a escuta e outros sentidos, exemplificando com a "estridência", a sensação acústica que faz ponte entre o sentido da audição e o da dor (CAESAR, 2017). Poderia apostar que os novos sentidos, recém-chegados à antiga lista de cinco, têm muito a ver com influências originadas pelas mudanças tecnológicas - seu condicionamento - sobre a dinâmica cultural (CAESAR, 2016), segundo a qual cada sentido desempenha maior ou menor papel conforme cada período da nossa história, e lugar em nossa geografia. Conforme já vem sendo proposto por diversos autores, a primazia do "ver" (MCLUHAN, 1964; HAVELOCK, 1986), por exemplo, iniciada com 
o registro visual de animais e coisas nas paredes das cavernas, passou por uma sequência de diferentes materiais e técnicas para armazenamento e manipulação de objetos visuais (KITTLER, 1985, 1986). As paredes da caverna marcavam apenas o começo da crescente ênfase na visualidade.

Por falta de meios de registro, os objetos dos demais sentidos ficaram passos atrás, até que, muito mais tarde, durante a virada para o século XX, Edison, Berliner e Cros inventaram equivalentes tecnológicos para o armazenamento de "objetos" de um deles o sentido bem mais volátil que a visão: a audição. Anteriormente, por falta de suporte para gravação de som, as atividades dependentes da audição e produção de som não tiveram condições de propiciar comparável status de "objetividade" para seus itens. Com exceção da partitura inventada para anotar qualidades precisas de sons específicos, somente após a chegada dessas invenções, ao conseguirmos gravar qualquer tipo de item acústico, permite-nos - hoje em dia - que se os considere como imagens, analogamente às imagens visuais. Uma discussão mais ampla pode ser estimulada pela leitura (BAYLE, 1993; CAESAR, 2012) e nos próximos parágrafos. Devemos acrescentar também, a essas mudanças devidas ao suporte de armazenamento, o fato de que os sentidos desenvolvem diferentes graus de importância de acordo com outro tipo de suporte, mais amplo: os lugares em que uma cultura vive. O geógrafo Yi-Fu Tuan discute esse tema em seu livro clássico Topophilia (TUAN, 1990), no qual traça a conexão entre afeto e percepção, nos rastros do carrapato do biólogo Jakob von Uexküll (UEXKÜLL, 1929 [2010]).

\section{A fina sonoridade}

Na década de 1960, Pierre Schaeffer escreveu: “[...] fions-nous à nos oreilles" (SCHAEFFER, 1967), para defender uma atitude fenomenológica e qualitativa, estimulando a "primazia da escuta", com endereço crítico ao projeto de tradição serialista da elektronische Musik. Schaeffer concentrou a maior parte de suas críticas na confiança que os alemães mantinham em uma acústica cartesiana regular, baseada em quantidades. Em sentido inverso, a técnica - mediada pelo sistema eletroacústico - da "música concreta", lidando "concretamente" com os "objets sonores" entre as mãos e a escuta. Ou seja, o novo modelo de intervenção sobre o objeto da escuta possibilitou aos 
compositores o contato direto com o "som" durante a feitura da obra, novidade somente permitida pela gravação/reprodução. Independentemente do projeto estético de Schaeffer - o abandono da mediação simbólica da notação para valorizar não mais o jogo de armar de símbolos, mas o jogo pesquisado pela escuta - um efeito paralisante se insinuou no mundo da composição. Pois, desde então, em decorrência exatamente do exercício da écoute réduite (SCHAEFFER, 1966) e dos "critérios de percepção" elaborados a partir dela, espalhou-se no campo da música de concerto contemporânea, para falar das qualidades desses "sons", uma estética baseada na escuta reduzida. Eis então a glorificação da sonoridade do "objet sonore", uma noção de método que se viu alçada a estética. Se você busca uma "estrutura" de suporte e justificativa para a composição musical, a fim de fornecer mais legitimidade do que as possibilidades potencialmente narrativas alojadas nos sons do cotidiano, está prestes a celebrar apenas os núcleos dos "sons" da música, perdendo assim o sabor de suas crostas crocantes, e para além delas, os odores e calores de seus vapores, e, dessas madeleines, as possíveis evocações.

Ao nos comprazermos com essas características "internas", ao eliminarmos as referências causais e de significado, supondo que sejam externas aos "sons", mantemonos ancorados na interpretação incorreta do objet sonore, projetado por Schaeffer para nos ajudar na descrição de itens isolados. O próprio conceito de "objeto sonoro" deve ser entendido como o foco inicial de uma linguagem operacional descritiva aplicada a "sons" isolados, desenvolvendo suas descrições por meio de classificação morfo-tipológica. Entretanto, para complicar as coisas, o próprio Schaeffer ensejou a estetização do objeto sonoro, explorando as qualidades morfo-tipológicas, a partir de 1958, expostas em primeiro plano em suas peças. Transformada, assim, em uma estética, fechou o invólucro do som.

É vernaculamente aceito ouvir que "sons" são objetos, mas também é útil ter em mente que eles ainda pertencem a uma categoria de "objetos voadores não identificados". A tarefa de contabilizar seus significados, complexidades, escopo e conotações por meio de traduções, aproximações, esquemas, analogias ou outras "reduções" é interminável. Para fins de análise e descrição musical, o esforço de redução pode parecer adequado, mas apenas para os setores musicais ou outros setores artísticos que não tentaram ir além das pretensões construtivistas e modernistas. 
Para outros, ele continua à beira da inutilidade. Tim Ingold afirmou que, assim como a luz é uma transportadora que não deve ser confundida com o objeto visual, o som é apenas o transportador e não o material transportado (INGOLD, 2007). Os sons, confundidos com o nome de seu veículo, são imagens transportadas para nossas mentes, assim como imagens visuais, cada uma em seu meio e velocidade específicos. Assim como "cheiros" são imagens olfativas que nos alcançam através do ar, e as qualidades táteis, também as imagens - não muito diferentes das sonoras - afetam nosso toque ao alcançar nossas peles, sendo o tímpano o mais leve (atenção à palavra!) de todas as peles. O som, como um objeto em si, não existe.

\section{Uma psicologia espacial}

Uma das técnicas mais empregadas na composição de música eletroacústica, já presente nos tempos analógicos, mas sobretudo na composição que faz uso de computadores, é a colocação, a movimentação e a transformação de sons no "espaço". Programas de computador, aliados a alto-falantes colocados em locais estratégicos, permitem controle bastante preciso do posicionamento e da projeção de trajetórias sonoras por toda a sala de concerto. Assim, otimizou a "espacialização", que já era uma reclamada propriedade da música eletroacústica, esta capaz de conduzir sons por rotas e lugares, distribuindo esses objetos entre todos os quadrantes dentro um "espaço de projeção sonora".

Existem muitos espaços e diagramas de projeção/difusão: em forma de cubo, hexágono, octógono ou apenas um quadrado, de acordo com cada salão. Já houve uma hemisférica, como o pavilhão de Osaka, construído para Stockhausen e a Coupole de Léo Küpper, e salões muito mais complexos, como o Pavilhão Phillips, onde Varèse e Xenakis estrearam em 1958. Invariavelmente, é uma sala vazia, que o artista mais ou menos prevê em sua mente durante seu trabalho de composição. Mas o objetivo do artigo é mais amplo do que uma crítica a um segmento artístico, pois se dirige a um modo de escutar.

[Intervalo para um comentário sobre a interferência das tecnologias em nossos modos de perceber. O histórico cientista da computação Alan Perlis (WANG, 2008) dizia: "linguagem de programação que não muda sua maneira de pensar, não vale a pena 
aprender”. Os programadores são uma parte importante do assunto em pauta, porque subjazem espacialmente às assinaturas composicionais dos autores. A outra parte importante é o próprio hardware.]

Antes mesmo dessa contribuição tecnológica que tendemos a esquecer, a noção de espaço como vazio é uma herança da evolução da moderna sala de concertos (THOMPSON, 2004). Quanto mais "neutralidade" numa sala de concerto, mais se constitui como o local ideal para o controle por computador da condução espacial do "som". No entanto o espaço não é necessariamente vazio, podendo ser entendido até como um ser vivo, ou afetivo, como já mencionado (TUAN, 1990). Suas qualidades dinâmicas, psicológicas e emocionais não são (ainda) objeto da manipulação de software. O simples gesto analógico de aproximar o microfone da boca, o close-miking, que nos anos 1950 transmitiu intimidade a muitos ouvintes, não tem tido - ainda - equivalente no mundo digital. Isso é, para mim, um alívio, pois ainda não estamos explorando a manipulação de uma conexão estreita entre as emoções e o espaço (CAESAR, 2004). ${ }^{5} \mathrm{Se}$ essas emoções podem fazer interseção com o espaço, e este com os "sons", como operaremos o corte entre "percepção" e "emoção"? John Cage entendeu perfeitamente bem o ser vivo do espaço de uma sala de concertos, ao deixá-lo ganhar vida por 4’33”.

\section{Escuta abrangente}

É preciso reforçar que esta pregação não é um pedido de supressão do treinamento de "escuta reduzida", etc., porque essa é uma entre várias outras experiências que nos permitem ter contatos parciais com a realidade sonora, e que todas elas devem ter seu reconhecimento. Minha própria pesquisa com sons de aves, insetos e anuros, pelo desconhecimento de suas linguagens, deve se servir de descrições bem ao gosto schaefferiano. Mas a promoção exclusiva ou central de ouvir apenas essas sonoridades “internas", ou "escuta timpânica”, como eu chamaria em um artigo (CAESAR, 2007), na

\footnotetext{
${ }^{5}$ Uma de nossas emoções mais primitivas, a angústia, é uma forma de medo relacionada à tensão, à falta de espaço onde se pode respirar livremente.
} 
verdade "reduz" apenas nossa capacidade de ouvir sons mais intelectuais, emocionais e demais possibilidades associativas.

Nisto segui o modelo de Marcel Duchamp, certamente um dos artistas mais interessantes do século passado, que criticou as limitações a uma arte voltada para a "retina". Coincidentemente, e quase simultaneamente a Duchamp, mas sem palavras faladas ou escritas, sem teorias, Erik Satie fez proposições semelhantes com algumas de suas peças. A mais radical delas, Vexations (1897) certamente não foi feita para agradar nossos ouvidos e nádegas, expondo-os à mesma melodia repetida 840 vezes.

Em desacordo com a certeza científica, esperada em textos acadêmicos, assumo um risco ao propor que a palavra "som" não tivesse, nos tempos antigos, o significado descritivo genérico que lhe damos agora: algo capaz de arrancar esses objetos sonoros de suas causas, significados, etc. Hoje, qualquer pessoa pode dizer que ouve o som da porta rangendo, em vez de simplesmente dizer que ouve uma porta rangendo. A palavra "som", interposta entre o ato de escutar e o rangido da porta, altera a experiência da porta rangente, enquanto a noção de som - ao individualizar a própria palavra - adquire importância. Dizer: "escutei um rangido de portas" produz uma sensação mais direta e objetiva da experiência. Difere de: "escutei o som de uma porta rangendo", frase em que o efeito descola da causa, podendo ser atribuído a outra causa que produza as mesmas características.

Não sei em que momento da História os humanos deixaram de se referir a escutas diretas, por exemplo os cantos de pássaros, os gritos de crianças, o murmúrio de águas e assim por diante, passando a interpor esse "som" genérico antes da designação do agente causador. Provavelmente a incerteza de identificação do agente soante. No mato, é mais fácil dizer-se que se escutou um pio de aves do que acertar com certeza o nome do agente. Acredito que deve ter havido um salto paradigmático, cuja consolidação provavelmente ocorreu junto ou logo após os tempos modernos.

Uma das minhas primeiras lembranças de ouvir no modo "reduzido" data de quando eu tinha quinze anos. Durante as fortes chuvas no Rio de Janeiro em 1966, que durou muitos dias, a cidade foi declarada em estado de calamidade pública. A rua onde eu morava, assim como outras ruas do bairro, se transformou em cursos d'água, correndo em direção à avenida principal - ela que já era um rio enterrado - a rua Lopes Quintas, 
no Jardim Botânico. Todas as ruas afluentes foram pavimentadas com paralelepípedos (também conhecidos como pavimentos ou sampietrinos), cada peça pesando ca. três quilos. Lembro-me de estar na janela da minha casa, ouvindo o som dessas pedras, enquanto elas rolavam puxadas pelo peso da água, passando em frente ao jardim, até chegarem às outras pedras que já estavam descendo a rua principal. Não podíamos ouvir nada além daquele som estrondoso e esmagador. Uma qualidade "suave" do som, uma massa textural de choques aleatórios molhados, eventualmente interrompida por solavancos mais evidentes, como se água e pedras derretessem em uma nova matéria, produzia um efeito sublime, cativando minha atenção para uma pausa agradável na audição, muito perto de um sentimento de beleza, um estado calmo tanto para minha mente quanto para meu corpo. Protegido da chuva e consciente da agudeza eventual no início de cada choque, e de suas variações imprecisas e ininterruptas, desfrutei acima de tudo a fusão dessa "massa complexa" com sua complexidade rítmica aleatória. Eu me envolvi com a massagem auditiva desses sons, ingenuamente inconsciente de suas consequências: a destruição que a chuva causaria à cidade.

Uma escuta abrangente é aquela em que atribuímos, aos sons, não somente os predicados plásticos de uma morfologia, nem só os atributos emprestados pelos sentidos vizinhos, porque é uma escuta em que a linha de corte entre percepção, sensação e sentimento está borrada. 


\section{Referências bibliográficas}

ALBAHARI, Miri. Analytical Buddhism. The two-tiered illusion of Self. London: Palgrave MacMillan, 2006.

BAYLE, François. Musique acousmatique propositions... ...positions. 1. Paris: Éditions Buchet/Chastel, 1993.

CAESAR, Rodolfo. Ela é tão tudo que é insignificante. Asa-Palavra, v. 1, 2004

As grandes orelhas da escuta (entre a teoria e a prática). In: Silvio Ferraz (ed.). Notas. Atos. Gestos. Rio de Janeiro: 7Letras, 2007.

O som como é: imagem; água e ar, seus suportes. In: (ed.). Pelas vias da dúvida. II Encontro de Pesquisadores em Artes. 1. Rio de Janeiro: PPGAV-UFRJ, v.1, 2012.

. O enigma de Lupe. Rio de Janeiro: Zazie Edições, 2016.

. O berro da arara: para "re(con)duzir" o objet sonore. Anais do XXVII Congresso da ANPPOM. Campinas, 2017.

CHION, Michel. Le son. Paris: Nathan, 1998.

DELL'ANTONIO, Andrew. Beyond structural listening: Postmodern modes of hearing. California: University of California Press, 2004.

DENNETT, Daniel C. Consciousness explained. New York: Little, Brown and Company, 1991.

HAVELOCK, Eric A. The muse learns to write. New York: Yale University Press, 1986.

IAZZETTA, Fernando. Música e mediação tecnológica. São Paulo: Perspectiva, 2009.

INGOLD, Timothy. Against Soundscape. In: CARLYLE, A. (Ed.). Autumn Leaves: Sound and the environment in artistic practice. Paris: Double Entendre, 2007.

KITTLER, Friedrich A. Discourse Networks 1800/1900. Stanford: Stanford University Press, 1985.

. Gramophone, Film, Typewriter. Stanford: Stanford University Press, 1986.

MAIER, Joost et al. A Multisensory Network for Olfactory Processing. Current Biology, v. 25, n. 20, 2015.

MCCLARY, Susan. Feminine Endings: Music, Gender, and Sexuality. New edition. University of Minnesota Press, 1991.

MCLUHAN, Marshall. Understanding Media: The Extensions of Man. Cambridge: The M.I.T. Press, 1964.

MERLEAU-PONTY, Maurice. A fenomenologia da percepção. Rio de Janeiro: Livraria Freitas Bastos, 1945. 
POLLAN, Michael. The Intelligent Plant Scientists debate a new way of understanding flora. The New Yorker, 2013.

ROUDNITSKA, Edmond. L'esthétique en question. Paris: Presses Universitaires de France, 1977.

SCHAEFFER, Pierre. Solfège de l'objet sonore. Paris: Éd. du Seuil - ORTF 1967.

SUBOTNICK, Rose R. Toward a deconstruction of structural listening: a critique of Schoenberg, Adorno, and Stravinsky. In: SUBOTKICK. R. R. (Ed.). Deconstructive variations: Music and Reason in Western Society. 1. Minnesota: University of Minnesota Press, 1995.

THOMPSON, Emily. The Soundscape of Modernity: Architectural Acoustics and the Culture of Listening in America, 1900-1933. Cambridge: MIT Press, 2004.

TUAN, Yi-Fu. Topophilia. A study of environmental perception, attitudes, and values. New York: Columbia University Press, 1990.

UEXKÜLL, Jakob. V. Umwelt und Innenwelt der Tiere. Lexington: University of Michigan, 1929 [2010].

WALLACE, Mark. Multisensory Perception: The Building of Flavor Representations. Current Biology, v. 25, n. 20, 2015.

WANG, Ge. The ChucK Audio Programming Language: "A Strongly-timed and On-the-fly Environ/mentality", Tese de Doutorado. Princeton University, 2008.

ZHOU, Wen et al. Olfaction Modulates Visual Perception in Binocular Rivalry. Current Biology, v. $20,2010$. 